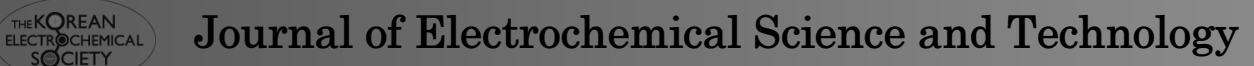

\title{
Preparation and Characterization of Electrodeposited Cad- mium and Lead thin Films from a Diluted Chloride Solution
}

\author{
Abbas Hamid Sulaymon ${ }^{1}$, Sawsan A. M. Mohammed ${ }^{2}$, and Ali Hussein Abbar ${ }^{3 *}$ \\ ${ }^{1}$ Environmental Engineering Department, University of Baghdad, Iraq \\ ${ }^{2}$ Chemical Engineering Department, University of Baghdad, Iraq \\ ${ }^{3}$ Chemical Engineering Department, Al-Qadissya University, Iraq
}

\begin{abstract}
$\mathrm{Cd}-\mathrm{Pb}$ thin films were electrodeposited from a diluted chloride solution using stainless steel rotating disc electrode. The linear sweep voltammograms of the single metallic ions show that electrodeposition of these ions was mass transfer control due to the plateau observed for different rotations at concentration (50 and $200 \mathrm{ppm}$ ). The voltammograms of binary system elucidate that electrodeposition process always start at cathodic potential located between the potential of individual metals. Currents transients measurements, anodic linear sweep voltammetry (ALSV) and atomic force microscopy (AFM) were used to characterize the electrocryatalization process and morphology of thin films. ALSV profiles show a differentiation for the dissolution process of individual metals and binary system. Two peaks of dissolution $\mathrm{Cd}-\mathrm{Pb}$ film were observed for the binary system with different metal ion concentration ratios. The model of Scharifker and Hills was used to analyze the current transients and it revealed that $\mathrm{Cd}-\mathrm{Pb}$ electrocrystalization processes at low concentration is governed by three dimensional progressive nucleation controlled by diffusion, while at higher concentration starts as a progressive nucleation then switch to instantaneous nucleation process. AFM images reveal that $\mathrm{Cd}-\mathrm{Pb}$ film electrodeposited at low concentration is more roughness than $\mathrm{Cd}-\mathrm{Pb}$ film electrodeposited at high concentrated solution.
\end{abstract}

Keywords: Electrodeposition, Anodic dissolution, Chronoamperometry, $\mathrm{Cd}-\mathrm{Pb}$ thin film, Electrocrystalization.

Received July 19, 2014 : Revised August 4, 2014 : Accepted September 4, 2014

\section{Introduction}

Electrodeposition of metals is an attractive method for the recovery of metal ions from different industrial effluents such as plating, metal finishing and electronics $[1,2]$. Some of these toxic metals of particular concern in treatment of industrial wastewaters are cadmium, and lead. Cadmium has been classified by U.S. Environmental Protection Agency as a probable human carcinogen. Chronic exposure of cad- mium results in kidney dysfunction and high levels of exposure will result in death. Lead can cause central nervous system, kidney and liver damage [3].

Various technologies such as precipitation, adsorption [4], biosorption [5], ion exchange [6], reverse osmosis [7], electrodialysis [8], ion exchangeassisted membrane separation [9-11] and electrochemical methods $[12,13]$ have been employed to remove these metals from various effluents. However electrochemical methods have been receiving greater

*Corresponding author. Tel.: 009647806898052

E-mail address: aliabbar68@yahoo.com

Open Access DOI: http://dx.doi.org/10.5229/JECST.2014.5.4.115

This is an Open Access article distributed under the terms of the Creative Commons Attribution Non-Commercial License (http://creativ ecommons.org/licenses/by-nc/3.0/) which permits unrestricted non-commercial use, distribution, and reproduction in any medium, provided the original work is properly cited. 
attention in recent years due to the distinctive advantages of environmental compatibility, versatility and safety.

The literatures of the removal of cadmium or lead from aqueous electrolytes using electrochemical deposition method are extensive [14-19]. Cadmium and lead may be existed simultaneously at different concentrations in the effluents from different industrial activities. No information can be found about the basic aspect of the electrochemistry of co-deposition of these two heavy metals. The knowledge of the nucleation and subsequent growth of electrodeposits at the nanometer scale promotes understanding the process as accurately as possible to achieve desired properties and applications, therefore the characterization of the deposited films is essential for any electrochemical removal process to investigate the morphology and mechanism of formation of such deposits [20,21].

The characterization and mechanism of electrodeposition of single $\mathrm{Pb}$ or $\mathrm{Cd}$ had been investigated extensively for different electrolytes and cathode materials [21-26]. References may be found for the characterization of binary systems such as $\mathrm{Cu}$ $\mathrm{Pb}$ [27,28], $\mathrm{Cu}-\mathrm{Cd}$ [29-31], however no information are found about the characterization of $\mathrm{Cd}-\mathrm{Pb}$ system. Most of the previous studies have been achieved for preparing alloys of $\mathrm{Cd}-\mathrm{Pb}$ from flouborate solutions of special properties $[32,33]$. To the best of authors' knowledge, no previous work has been conducted to characterization the $\mathrm{Pb}-\mathrm{Cd}$ films electrodeposited from diluted chloride medium using stainless steel as cathode material.

Based on the above consideration, the present work was carried out to prepare and characterize $\mathrm{Pb}-\mathrm{Cd}$ thin films with different metal ion concentration ratios electrodeposited on stainless steel cathode from diluted chloride solution. Stainless steel is very effective as a cathode for metal removal from wastewaters, and is an inexpensive material compared to graphite felt or reticulated vitreous carbon [34-36].

$\mathrm{The} \mathrm{Cd}-\mathrm{Pb}$ films were electrodeposited and dissolved by a cathodic and anodic linear sweep of electrode potential in the solution containing ions of both metals and in the $\mathrm{NaCl}$ solution, respectively. Another procedure used here was based on potentiostatic transients of current where the dependence between current and experiment time for the formation and growth of $\mathrm{Cd}-\mathrm{Pb}$ films at a constant negative potential is recorded.

\section{Experimental Work}

The electrochemical experiments were carried out in a conventional three-electrode cell (Pyrex glass). A $0.0314 \mathrm{~cm}^{2}$ stainless steel (316-AISI) rotating disc electrode (RDE) was used as a working electrode. Its surface was polished before each experiment with emery paper of grade $600(3 \mathrm{M})$. A platinum plate $\left(0.35 \mathrm{~cm}^{2}\right)$ and a saturated calomel electrode were used as a counter and a reference electrode respectively. Electrochemical experiments were controlled with a potentiostat PGSTAT30 (Autolab), under a computerized control. Chemicals used were $\mathrm{PbCl}_{2}$, $\mathrm{CdCl}_{2}, \mathrm{NaCl}$, and boric acid (reagent grade). The electrolytic solutions were freshly prepared with doubly distill water. The $\mathrm{Cd}-\mathrm{Pb}$ ratios were $1: 1,1: 4,4: 1$ corresponding to concentration ratios as $(50: 50)$, (200:200), (50:200) and (200:50) ppm respectively. The supporting electrolyte was $0.5 \mathrm{M} \mathrm{NaCl}$ and $0.1 \mathrm{M}$ $\mathrm{H}_{3} \mathrm{BO}_{3}$ with final $\mathrm{pH}$ of 5 adjusted by using $\mathrm{NaOH}$ or $\mathrm{HCl}$. It is important to point out that such solutions were prepared to resemble the concentration of metallic ions and $\mathrm{pH}$ of a typical composition of an effluent of plating industries [35]. All experiment were performed at $25 \pm 1^{\circ} \mathrm{C}$. All cathodic linear sweep voltammetry experiments (LSV) were performed at $5 \mathrm{mV} \mathrm{s}^{-1}$ (scanning from positive to negative direction). The applied potentials for potentiostatic experiments were determined based on the results of voltammetric experiments. The ALSV experiments were performed in a cell of the same type. In this cell saturated calomel electrode (SCE) used as a reference electrode. The deposition on the RDE was washed with extra pure water and transferred into the cell for the ALSV analysis. ALSV analysis was performed in solution of $0.5 \mathrm{M} \mathrm{NaCl}, 0.1 \mathrm{M} \mathrm{H}_{3} \mathrm{BO}_{3}$, and $\mathrm{pH}=5$ with a sweep rate of $2 \mathrm{mV} \mathrm{s}^{-1}$ at $1200 \mathrm{rpm}$. In all cases after the dissolution no traces of the deposit left on the St.St surface were detected, indicating complete dissolution of the deposit. Before each experiment (in the case of deposition and ALSV), the electrolyte was purged with nitrogen $(99.999 \%)$ for $30 \mathrm{~min}$, while a nitrogen atmosphere was maintained over the solution during the experiment to prevent contact with oxygen. In the chronoamperometry experiments, series of potential step experiments at different increments were achieved in stationary 
solution by stepping from an open circuit potential to the selected final potentials based on the result of linear sweep voltammograms. The AFM analysis was performed using SPM-AA3000 (Angestrom Advanced Inc., USA) in contact mode. AFM images were recorded over scan area $(2 \mu \mathrm{m} \times 2 \mu \mathrm{m})$. The XRD measurement was achieved by using XRD6000(Shimadzu co., Japan).

\section{Results and Discussion}

\subsection{Voltammetric measurements}

Fig. 1 (a,b,c,d). shows polarization curves corresponding to lead and cadmium electrodeposited on stainless steel rotating disc electrode for several rotation speeds (400, 800, 1200, 1600, and $2000 \mathrm{rpm})$ at concentration of 50 and $200 \mathrm{ppm}$ respectively. The voltammograms show a limiting current zone in the potential range -725 to $-900 \mathrm{mV}$ vs. SCE for lead, and -900 to $-1100 \mathrm{mV}$ for cadmium. Under such conditions, the reaction rate is limited by the mass trans-

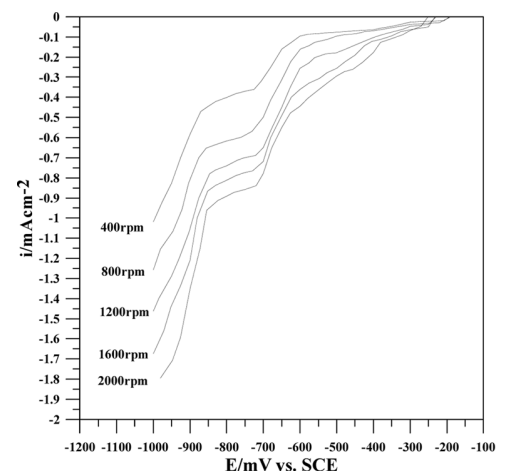

(a)

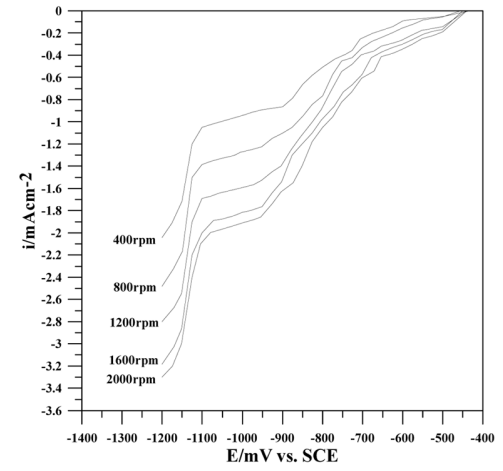

(c) port rate and the limiting current at the smooth rotating disc in laminar flow can be predicted by the Levich equation [37]:

$$
I_{L}=0.62 z F A D^{2 / 3} \omega^{1 / 2} v^{-1 / 6} c_{b}
$$

Where $I_{L}$ is the limiting current $\mathrm{mA}, \mathrm{A}$ is the area of electrode $\mathrm{cm}^{2}, z$ is the number of electron, $F$ is Faraday constant, $D$ is the diffusion coefficient $\mathrm{cm}^{2} \mathrm{~s}^{-1}, \omega$ is the rotation rate $\mathrm{rad} \mathrm{s}^{-1}, v$ is the kinematic viscosity of the electrolyte $\mathrm{cm}^{2} \mathrm{~s}^{-1}$ and $\mathrm{c}_{\mathrm{b}}$ is the bulk concentration $\mathrm{molcm}^{-3}$.

To investigate whether the reduction of $\mathrm{Cd}$ and $\mathrm{Pb}$ occurred under mass transfer condition, the limiting currents were calculated from the polarization curves and plotted against $\omega^{1 / 2}$ Fig. 2. The limiting current was found at the middle point of a straight line that follows the plateau region and is limited by $\mathrm{E}_{\max }$ and $\mathrm{E}_{\min }$ [38]. These values are the points at which the straight line departs from $I$ vs. $E$ curve. The results indicate that the reduction of $\mathrm{Cd}$ and $\mathrm{Pb}$ is under mass transfer control.

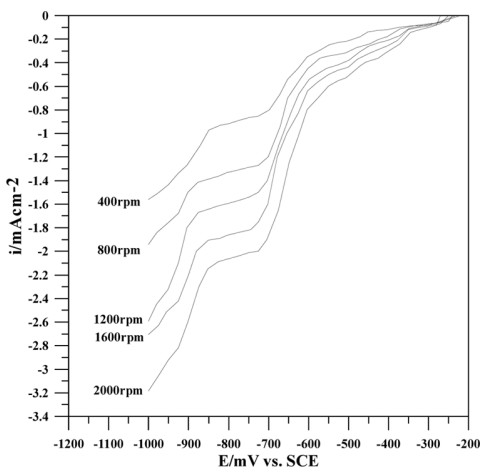

(b)

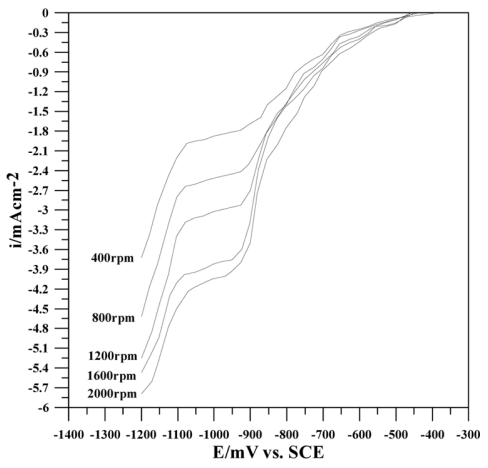

(d)

Fig. 1. Linear voltammetric curves for reduction of lead and cadmium on stainless steel rotating disc electrode at different rotation speeds: a)Pb at $50 \mathrm{ppm}, \mathrm{b}) \mathrm{Pb}$ at $200 \mathrm{ppm}, \mathrm{c}) \mathrm{Cd}$ at $50 \mathrm{ppm}, \mathrm{d}) \mathrm{Cd}$ at $200 \mathrm{ppm}$. Supporting electrolyte $(0.5 \mathrm{M}$ $\left.\mathrm{NaCl}+0.1 \mathrm{M} \mathrm{H}_{3} \mathrm{BO}_{3}\right), \mathrm{pH}=5$. 
Fig. 3 (a,b,c,d). Shows polarization curves for electrodeposition of $\mathrm{Cd}-\mathrm{Pb}$ binary and single systems from chloride solution at $1200 \mathrm{rpm}$. It can be seen that at low current densities $\left(-0.3 \mathrm{mAcm}^{-2}\right)$, the polar- ization curve of $\mathrm{Pb}$ lies at considerably more positive potentials than $\mathrm{Cd}$. $\mathrm{Pb}$ deposition begins earlier than $\mathrm{Cd}$. This result indicates that $\mathrm{Pb}$ is the noble metal.

At higher current densities, a crossing of lead and

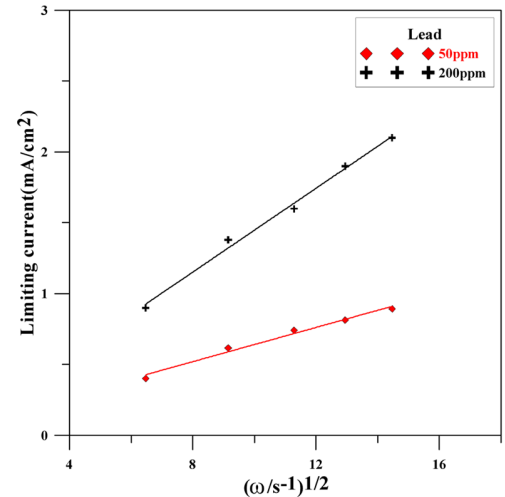

(a)

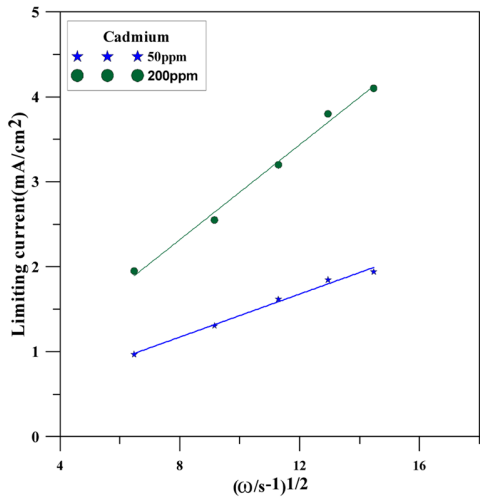

(b)

Fig. 2. Levich plots for the limiting currents taken at potentials of $-790 \mathrm{mV}$ vs. $\mathrm{SCE}$ for $\mathrm{Pb}$ (a) and $-1025 \mathrm{mV}$ for $\mathrm{Cd}(\mathrm{b})$ at two concentrations 50 and $200 \mathrm{ppm}$. Supporting electrolyte $\left(0.5 \mathrm{M} \mathrm{NaCl}+0.1 \mathrm{M} \mathrm{H}_{3} \mathrm{BO}_{3}\right), \mathrm{pH}=5$.

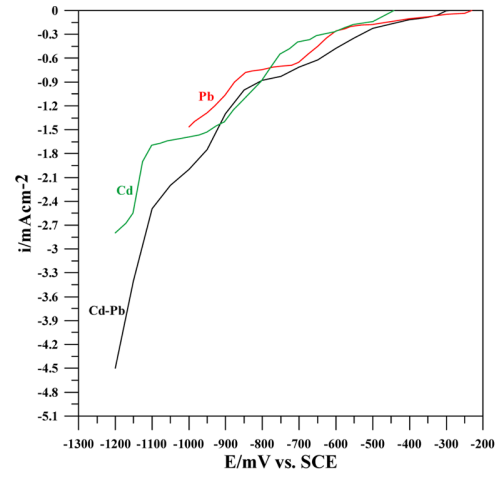

(a)

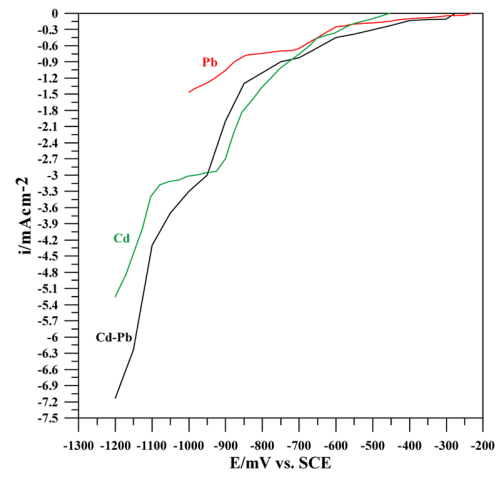

(c)

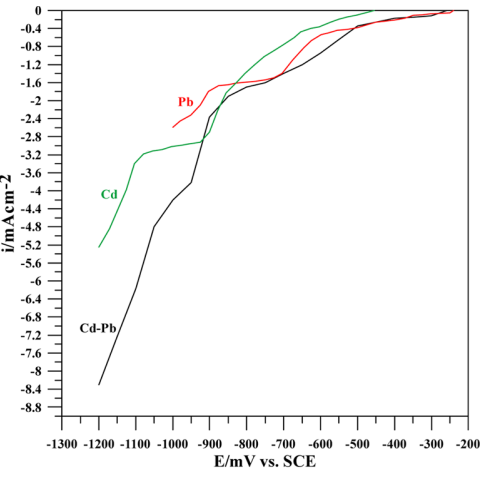

(b)

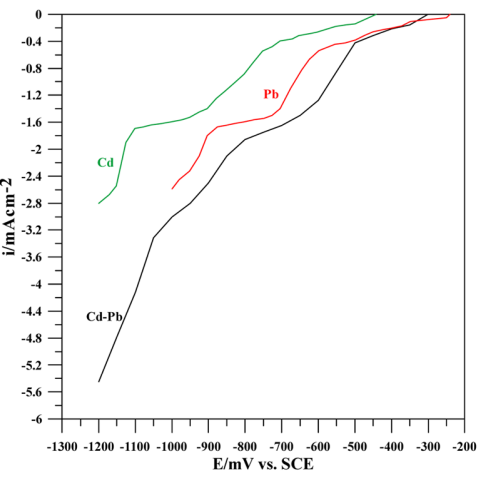

(d)

Fig. 3. Linear voltammetric curves for reduction of cadmium-lead on stainless steel rotating disc electrode at (1200 rpm) in comparison with individual single metal curves: a) $\mathrm{Cd}, \mathrm{Pb}$ at $50 \mathrm{ppm}$, b) $\mathrm{Cd}, \mathrm{Pb}$ at $200 \mathrm{ppm}, \mathrm{c}) \mathrm{Cd}$ at $200 \mathrm{ppm}, \mathrm{Pb}$ at $50 \mathrm{ppm}$, d) $\mathrm{Cd}$ at $50 \mathrm{ppm}, \mathrm{Pb}$ at $200 \mathrm{ppm}$, supporting electrolyte $\left(0.5 \mathrm{M} \mathrm{NaCl}+0.1 \mathrm{M} \mathrm{H}_{3} \mathrm{BO}_{3}\right), \mathrm{pH}=5$. 
cadmium curves was observed for all concentration ratios except for $\mathrm{Pb}$ at concentration $200 \mathrm{ppm}$ with $\mathrm{Cd}$ at concentration $50 \mathrm{ppm}$. This crossing may be ascribed to a large increase of hydrogen evolution on cadmium. It is cleared that the polarization curves of $\mathrm{Cd}-\mathrm{Pb}$ system start at potential lies between the initial potentials of the individual metals. The codeposition enables the less noble metal $(\mathrm{Cd})$ to deposit at more positive potentials and causes more noble metal $(\mathrm{Pb})$ to deposit at more cathodic potentials than individual deposition case [39]. At more negative cathodic potential the polarization curve for $\mathrm{Cd}-\mathrm{Pb}$ system is higher than the individual curves for all concentration ratios. All the polarization curves for $\mathrm{Cd}-\mathrm{Pb}$ system exhibit two well defined regions with no plateau in all cases. The first region start at $-550 \mathrm{mV}$ vs. SCE referred to codeposition of $\mathrm{Pb}$ and $\mathrm{Cd}$ in which lead is controlled while the second region start at $-850 \mathrm{mV}$ vs. $\mathrm{SCE}$ in which the cadmium is the predominated. At cathode potential more negative than $-1100 \mathrm{mV}$ vs. SCE hydrogen evaluation is increased more rapidly.

\subsection{Anodic linear sweep voltammetry}

ALSV has been developed as an appropriate in situ technique for electrochemical characterization of the phase composition of thin layers of electrodeposited alloys [40,41]. In the present work, this technique was adapted to characterize the $\mathrm{Cd}-\mathrm{Pb}$ films electrodeposited under potentiostatic conditions. Therefore, the electrode potential was maintained at $-1025 \mathrm{mV}$ vs. SCE for $5 \mathrm{~min}$ to form the deposits of $\mathrm{Cd}-\mathrm{Pb}$ and then anodic dissolution was carried out using a slow sweep rate $(2 \mathrm{mV} / \mathrm{s})$ in the positive direction. The deposition and dissolution steps were achieved at $1200 \mathrm{rpm}$. The ALSV curves of dissolution of single $\mathrm{Pb}, \mathrm{Cd}$, and $\mathrm{Cd}-\mathrm{Pb}$ binary system are shown in Fig. 4 $(a, b, c, d)$. The well separated two anodic peaks, coinciding with those obtained with corresponding single
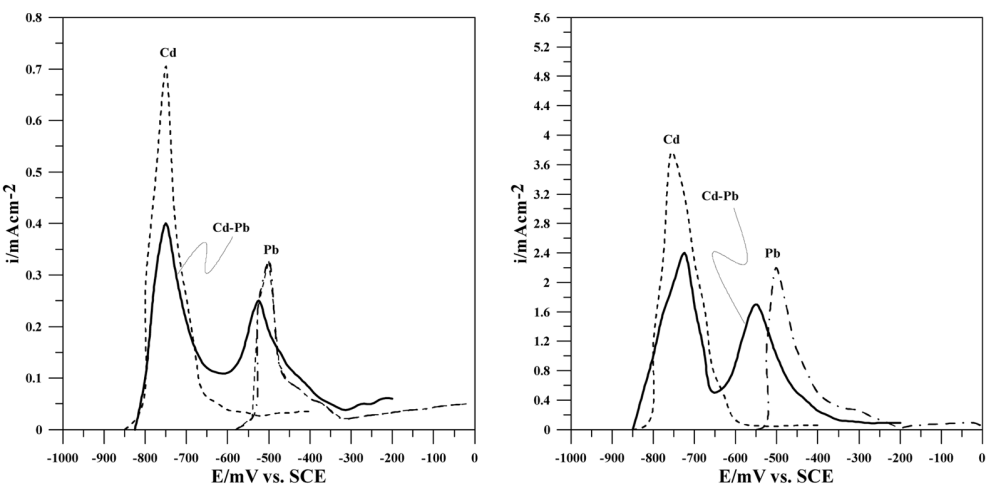

(a)

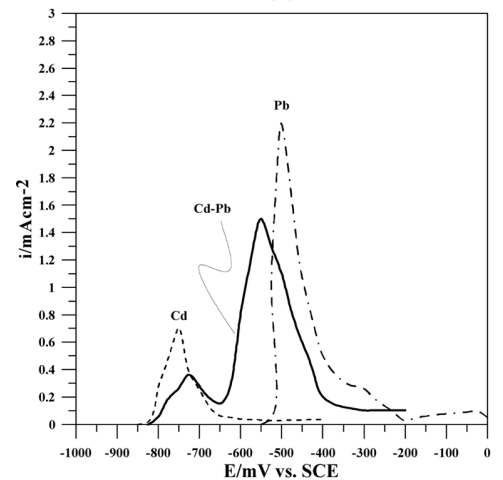

(c)

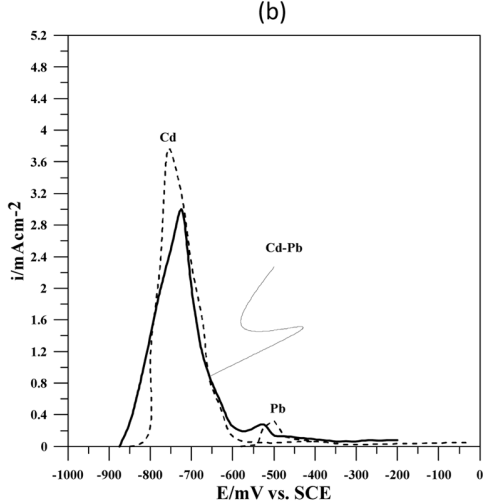

(d)

Fig. 4. ALSV curves recorded at the sweep rate of $2 \mathrm{mVs}^{-1}$ for dissolution of $\mathrm{Pb}, \mathrm{Cd}$ and $\mathrm{Cd}-\mathrm{Pb}$ binary system electrodeposited from electrolytes containing (a) $\mathrm{Cd}, \mathrm{Pb}$ at $50 \mathrm{ppm}$,(b) $\mathrm{Cd}, \mathrm{Pb}$ at $200 \mathrm{ppm}$,(c) $\mathrm{Cd}$ at $50 \mathrm{ppm}, \mathrm{Pb}$ at $200 \mathrm{ppm}$, (d) $\mathrm{Cd}$ at $200 \mathrm{ppm}, \mathrm{Pb}$ at $50 \mathrm{ppm}$, Supporting electrolyte $\left(0.5 \mathrm{M} \mathrm{NaCl}+0.1 \mathrm{M} \mathrm{H}_{3} \mathrm{BO}_{3}\right), \mathrm{pH}=5$, rotation $=1200 \mathrm{rpm}$, deposition time $=5$ min. 
metal deposits, clearly demonstrate the existence of two different phases. Fig. 5 shows the phase diagram of $\mathrm{Cd}-\mathrm{Pb}$ alloy which is eutectic type with no miscibility between $\mathrm{Pb}$ and $\mathrm{Cd}$ in the solid phase [42]. Since the interaction between $\mathrm{Pb}$ and $\mathrm{Cd}$ in the solid phase is negligible therefor the free energy of each component should not be changed and the reversible potential of each component in the alloy should be similar to the reversible potential of pure components of the corresponding grain size leading to two separated peaks of dissolution of each component from the alloy. The peak of dissolution of $\mathrm{Pb}$ from binary system is shifted to the more negative potential than dissolution of single $\mathrm{Pb}$ while $\mathrm{Cd}$ is shifted to more positive potential than dissolution of single $\mathrm{Cd}$. This shifting was not exceeded $50 \mathrm{mV}$ in almost cases.

It was found that ALSV can be used as a method of phase composition determination of alloys superior to the X-ray method [27,36, and 43]. The ALSV

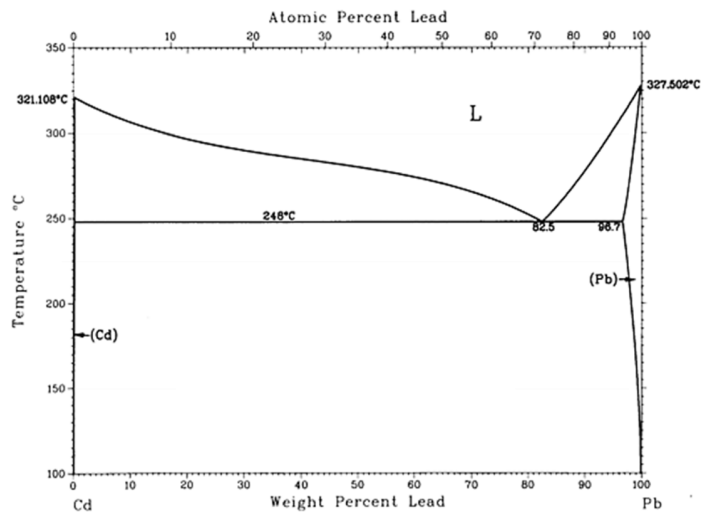

Fig. 5. The phase diagram of $\mathrm{Cd}-\mathrm{Pb}$ binary alloy. "Reprinted with permission from ref.42".

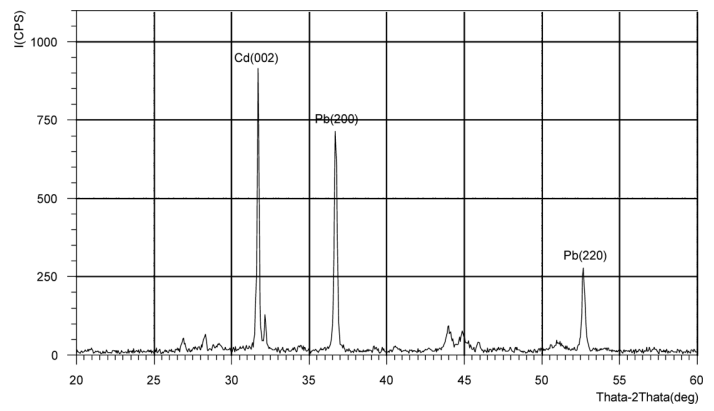

Fig. 6. XRD patterns of electrodeposited $\mathrm{Cd}-\mathrm{Pb}$ film prepared from electrolyte containing $\mathrm{Cd}-\mathrm{Pb}(200: 200)$ as concentration ratio in ppm. Supporting electrolyte $(0.5 \mathrm{M}$ $\left.\mathrm{NaCl}+0.1 \mathrm{M} \mathrm{H}_{3} \mathrm{BO}_{3}\right), \mathrm{pH}=5,1200 \mathrm{rpm}$. enables quantitative analysis of the phase composition in that the amount of charge under a given peak, contrasted with the total charge under the ALSV, can render the content of the phase whose dissolution is reflected in the peak. Therefore the wt $\%$ of cadmium is approximately 1.5 times that of lead for the films electrodeposited from solutions containing either $\mathrm{Cd}$ $\mathrm{Pb}(50: 50)$ or $\mathrm{Cd}-\mathrm{Pb}(200: 200)$ since the charge under the peak of cadmium is higher than that for lead,consequently the $\mathrm{wt} \% \mathrm{~Pb}$ is five times that of $\mathrm{Cd}$ for film deposited from solution with $\mathrm{Cd}-\mathrm{Pb}(50: 200)$. Fig. 6 shows the XRD analysis for film electrodeposited from solution containing $\mathrm{Cd}-\mathrm{Pb}(200: 200)$ which is coincided with ALSV results.

\subsection{Chronoamperometric measurements}

Chronoamperometry $(\mathrm{CP})$ was used as an electrochemical technique suitable for electrochemical nucleation mechanisms studies [44]. There are several published methods that utilize the coordinates of chronoamperometric peaks to determine nucleation mechanisms and parameters related to nucleation [45], among which the model developed by Scharifker and Hills [46] is the most widely used. This model allows simple and rapid classification of experimental transients into the two limiting nucleation mechanisms-instantaneous or progressive. Instantaneous nucleation, Eqs. (2 and 3), corresponds to a slow growth of nuclei on a small number of active sites, all activated at the same time, while progressive nucleation, Eqs. (4 and 5), corresponds to fast growth of nuclei on many active sites, activated during the course of electroreduction [47]:

For instantaneous nucleation

$$
\begin{aligned}
& i=\frac{z F \pi(2 D c)^{3 / 2} M^{1 / 2} N_{o} t^{1 / 2}}{\rho^{1 / 2}} \\
& \frac{i^{2}}{i_{m}^{2}}=\frac{1.9542}{\frac{t}{t_{m}}}\left\{1-\exp \left[-1.2564\left(\frac{t}{t_{m}}\right)^{2}\right]\right\}^{2}
\end{aligned}
$$

For progressive nucleation

$$
\begin{aligned}
& i=\frac{2 z F \pi(2 D c)^{3 / 2} M^{1 / 2} A N_{o} t^{3 / 2}}{3 \rho^{1 / 2}} \\
& \frac{i^{2}}{i_{m}^{2}}=\frac{1.2254}{\frac{t}{t_{m}}}\left\{1-\exp \left[-2.3347\left(\frac{t}{t_{m}}\right)^{2}\right]\right\}^{2}
\end{aligned}
$$


Where $i$ is the current density $\left(\mathrm{Acm}^{-2}\right), \mathrm{A}$ is the nucleation rate constant $\left(\mathrm{s}^{-1}\right), \mathrm{N}_{\mathrm{o}}$ is the number density of nuclei $\left(\mathrm{cm}^{-2}\right), \mathrm{z}, \mathrm{F}, \mathrm{M}, \rho, \mathrm{D}, \mathrm{c}$ and $\mathrm{t}$ are the number of electron, Faraday constant, the atomic weight, density of the depositing metal $\left(\mathrm{gcm}^{-3}\right)$, the diffusion coefficient $\left(\mathrm{cm}^{2} \mathrm{~s}^{-1}\right)$, the concentration of the eletrodepositing species $\left(\mathrm{mol} \mathrm{cm}{ }^{-3}\right)$ and the time of nucleation(s) respectively. $i_{\mathrm{m}}$ and $t_{\mathrm{m}}$ are the current density and the time, as respective peak coordinates. The plots of experimental current transients $\left(i / i_{m}\right)^{2}$ versus $\left(t / t_{\mathrm{m}}\right)$ coordinates fall at either of these two limiting cases.

The first twenty seconds of current transients recorded at three potential steps for all single and binary system are presented in Figs. 7(a,c), 8(a,c), $9(\mathrm{a}, \mathrm{c})$, and 10(a,c). Each of the chronoamperograms in these figures were characterized by the initial current increase as a response to the applied potential, formation of a peak characteristic for nucleation, and final convergence to the limiting current corresponding to linear diffusion to a planar electrode.

Initial current increase is due to the increase of sur-

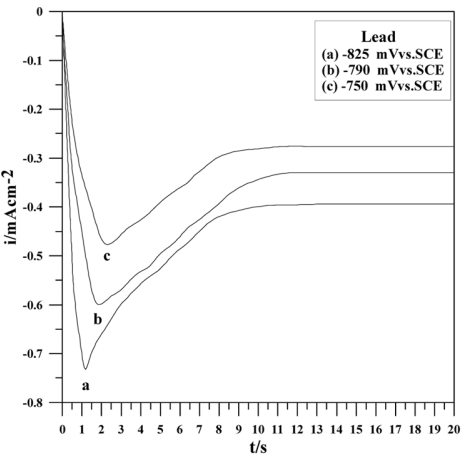

(a)

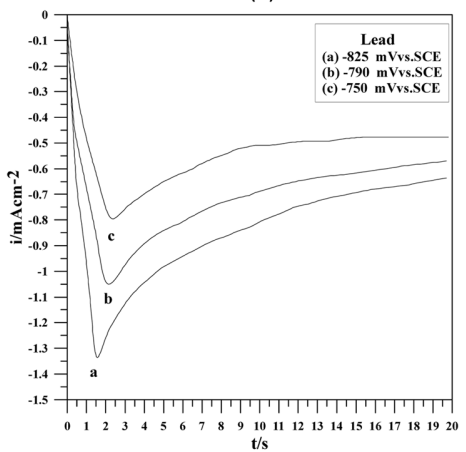

(c) face area whenever the nucleation is involved. As nucleation progresses, the nuclei will begin overlapping. Each nucleus will define its own diffusion zone through which metal has to diffuse, representing the mass-supplying mechanism for continuation of growth. Since the diffusion zones are much larger than the underlying nuclei, the overlapping zones would eventually include the entire electrode area. Further reaction is strictly controlled by the rate of mass transfer through the control area of the diffusion zone. Within the diffusion zone, growth of alreadyestablished metal nuclei can continue, or additional nucleation can be initiated on various sites, both governed by the steady state conditions [44].

The experimental current transients plotted in reduced current-time coordinates, along with the lines for instantaneous and progressive nucleation (solid and dashed lines, for Eqs. 3 and 5) are shown in Figs. 7(b,d), 8(b,d), 9(b,d), and 10(b,d). The reduced current transients of lead at concentration $50 \mathrm{ppm}$ follow the instantaneous nucleation model for potential steps equal or higher than $-790 \mathrm{mV}$ Fig.

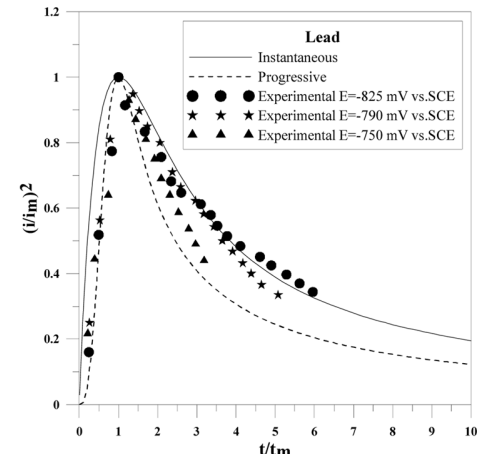

(b)

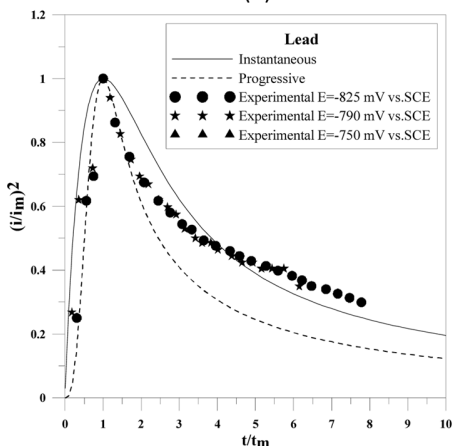

(d)

Fig. 7. Chronoamperometry of $\mathrm{Pb}$ electrodeposition on stainless steel electrode with the corresponding Scharifker-Hills' model: a,b)Pb at $50 \mathrm{ppm}, \mathrm{c}, \mathrm{d}) \mathrm{Pb}$ at $200 \mathrm{ppm}$, supporting electrolyte $\left(0.5 \mathrm{M} \mathrm{NaCl}+0.1 \mathrm{M} \mathrm{H}_{3} \mathrm{BO}_{3}\right), \mathrm{pH}=5$. 
7(b). At potential step $-750 \mathrm{mV}$, a small deviation from instantaneous model has been observed due to the mixed control of diffusion and charge transfer in this region. For lead at concentration 200 ppm, the reduced current transients follow the progressive at $\left(\mathrm{t} / \mathrm{t}_{\mathrm{m}}<2\right)$ then switched to the instantaneous nucleation models at higher values of $\left(\mathrm{t} / \mathrm{t}_{\mathrm{m}}>2\right)$ for all three potential steps Fig. 7(d). However the general behavior is in agreement with previous work using chloride medium at higher concentration of lead [48].

The nucleation mechanism of cadmium at concentration $50 \mathrm{ppm}$ is progressive for all three potential steps Fig. 8(b). At higher concentration (200 ppm), the situation is different, the reduced current transients follow the progressive at $\left(\mathrm{t} / \mathrm{t}_{\mathrm{m}}<3\right)$ then switched to the instantaneous nucleation models at higher values of $\left(\mathrm{t} / \mathrm{t}_{\mathrm{m}}>3\right)$ for all three potential steps Fig. 8(d). The mechanism of $\mathrm{Cd}$ electrodeposition has been studied on different metal substrates such as: $\mathrm{Cd}, \mathrm{Ni}$, $\mathrm{Cu}, \mathrm{Se}, \mathrm{Pt}$, glassy carbon, and $\mathrm{SnO}_{2}$ [49-51]. The cited studies reveal that the growth of Cd crystals has been catalogued as complex due to existence of adsorption and nucleation processes. Gunawardena et al. [49] found that cadmium electrodeposition onto glassy carbon is progressive in perchlorate and sulfate media while no nucleation occurred in nitrate solution. Edgar et al. [25] studied the electrocrystalization of cadmium on anodically formed titanium oxide using diluted sulfate medium and found that the nucleation process is fitted to progressive model. Therefore it is cleared that the nucleation mechanism tend to instantaneous model as the concentration increased.

The reduced current transients of $\mathrm{Cd}-\mathrm{Pb}$ electrodeposition for three potential steps at concentration ratio $\mathrm{Cd}-\mathrm{Pb}(50: 50)$ is shown in Fig. 9(b). It is cleared that the transients follow the progressive model. Accordingly it may be concluded that the mechanism of nucleation in the codeposition of lead with cadmium is controlled by cadmium which is progressive when cadmium is alone or mixed with lead.

For $\mathrm{Cd}-\mathrm{Pb}$ system at higher concentration $\mathrm{Cd}-\mathrm{Pb}$ (200:200), the reduced current transients follow the progressive at $\left(t / t_{m}<2.5\right)$ then switched to the instan-

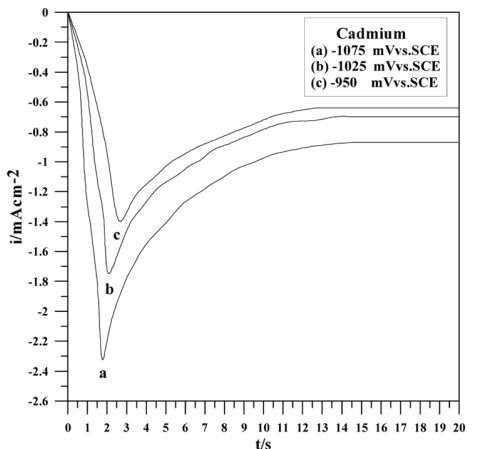

(a)

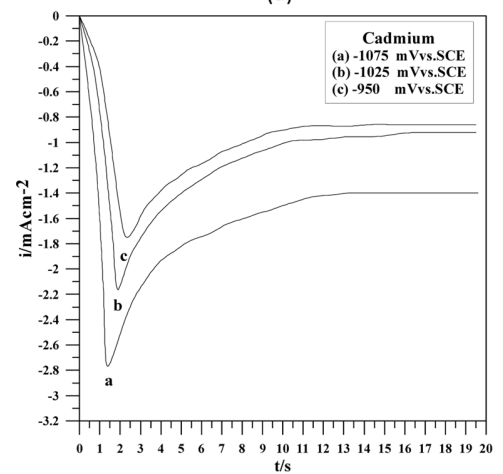

(c)

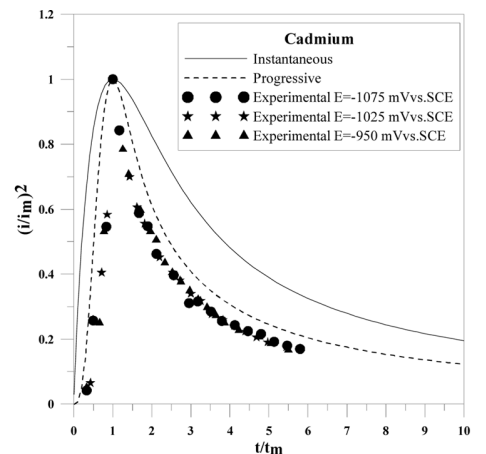

(b)

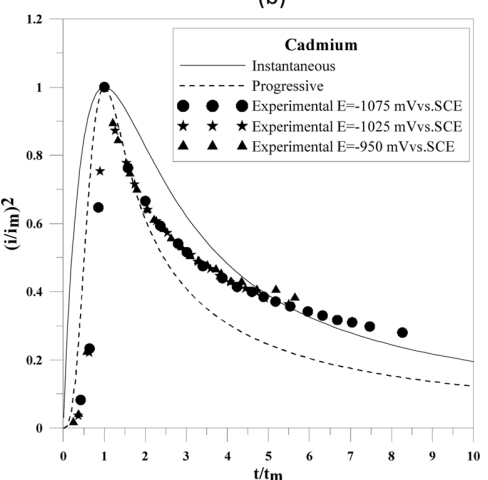

(d)

Fig. 8. Chronoamperometry of Cd electrodeposition on stainless steel electrode with the corresponding Scharifker-Hills' model: a,b)Cd at 50ppm, c,d)Cd at $200 \mathrm{ppm}$, supporting electrolyte $\left(0.5 \mathrm{M} \mathrm{NaCl}+0.1 \mathrm{M} \mathrm{H}_{3} \mathrm{BO}_{3}\right), \mathrm{pH}=5$. 

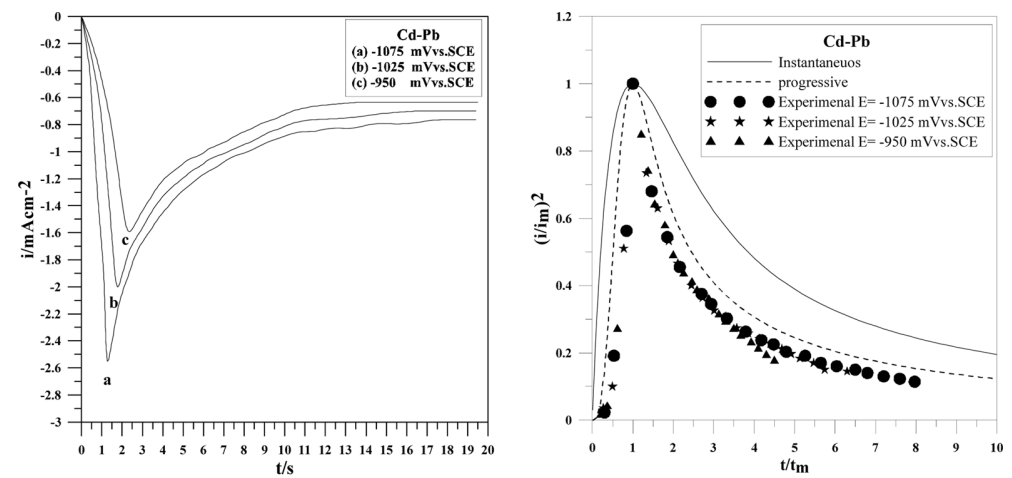

(a)

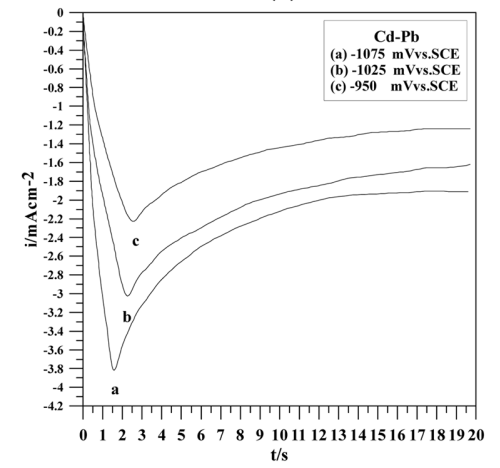

(b)

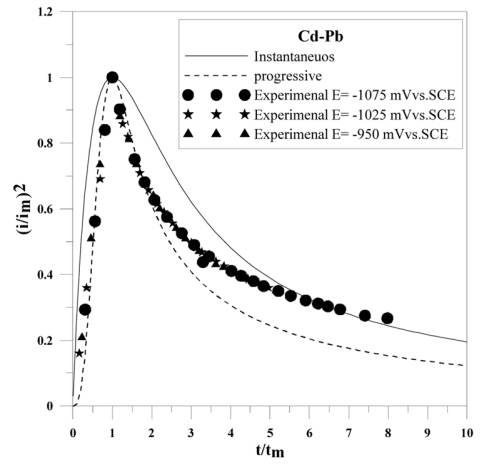

(d)

Fig. 9. Chronoamperometry of $\mathrm{Cd}-\mathrm{Pb}$ electrodeposition on stainless steel electrode with the corresponding SCHARIFKERHills' model: a,b)Cd and $\mathrm{Pb}$ at $50 \mathrm{ppm}, \mathrm{c}, \mathrm{d}) \mathrm{Cd}$ and $\mathrm{Pb}$ at $200 \mathrm{ppm}$, supporting electrolyte $\left(0.5 \mathrm{M} \mathrm{NaCl}+0.1 \mathrm{M} \mathrm{H}_{3} \mathrm{BO}_{3}\right)$, $\mathrm{pH}=5$.

taneous nucleation model at higher values of $(\mathrm{t} /$ $\left.t_{m}>2.5\right)$ for all three potential steps Fig. 9(d).The most interesting behavior occurred in $\mathrm{Cd}-\mathrm{Pb}$ system of concentration ratios (50:200) and (200:50) are shown in Fig. 10 (b, d). The reduced current transients exhibit progressive nucleation at $\left(\mathrm{t} / \mathrm{t}_{\mathrm{m}}<3\right)$ switching to instantaneous nucleation after that is approximately similar to the nucleation mechanism of $\mathrm{Cd}-\mathrm{Pb}$ system with higher concentration $\mathrm{Cd}-$ $\mathrm{Pb}(200: 200)$. Hence the mechanism of nucleation in the codeposition of lead with cadmium is controlled by instantaneous nucleation when the concentration of either ions is increased.

\section{Characterization of the deposits}

Atomic force microscopy is an excellent tool to study morphology and texture of diverse surfaces. The versatility of this technique allows meticulous observations and evaluations of the textural and morphological characteristics of the films, showing better facilities than other microscopic methods [52]. Table 1.shows the results of AFM measurements while Figs. 11 and 12 show the AFM images for the cathode substrate (St.St) before using, Pb films electrodeposited at electrode potential $-790 \mathrm{mV}$ vs. SCE at concentrations 50 and 200ppm, Cd films electrodeposited at electrode potential $-1025 \mathrm{mV}$ at concentrations 50 and $200 \mathrm{ppm}$, and $\mathrm{Cd}-\mathrm{Pb}$ films electrodeposited at electrode potential $-1025 \mathrm{mV}$ from different concentration ratios.

The most important parameters of AFM measurements are average roughness, root mean square roughness (Sq), surface skewness, and surface kurtosis [53]. The AFM analysis of cathode substrate shows that Sq is $0.0589 \mathrm{~nm}$, i.e. the surface of St.St is smooth confirming the mechanical polishing is well. The Sq values are 1.9 and $1.52 \mathrm{~nm}$ for $\mathrm{Pb}$ electrodeposited at concentrations 50 and $200 \mathrm{ppm}$ respectively and 1.65 and $1.18 \mathrm{~nm}$ for Cd electrodeposited at concentrations 50 and $200 \mathrm{ppm}$ respectively. The results indicated that lead was rougher than cadmium 

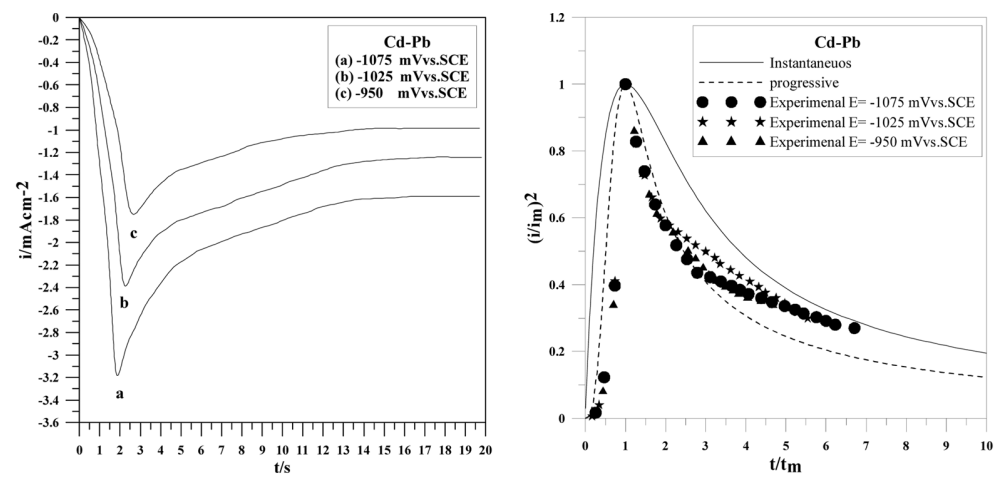

(a)

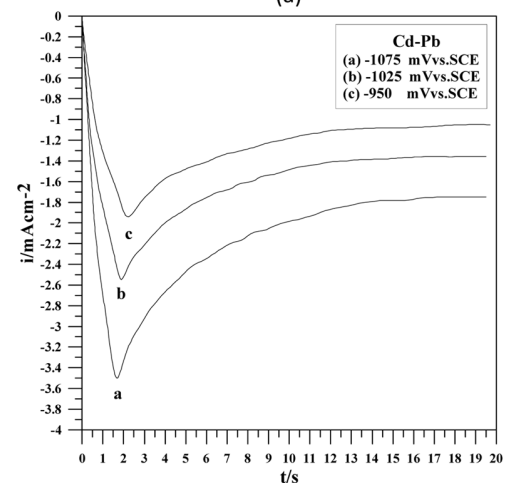

(c)

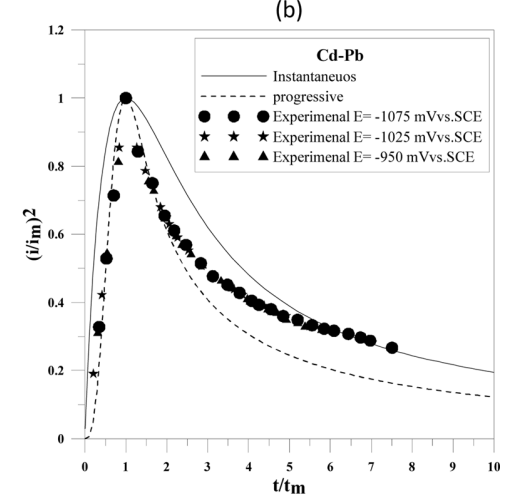

(d)

Fig. 10. Chronoamperometry of $\mathrm{Cd}-\mathrm{Pb}$ electrodeposition on stainless steel electrode with the corresponding SCHARIFKERHills' model: a,b) $\mathrm{Cd}$ at $50 \mathrm{ppm}, \mathrm{Pb}$ at $200 \mathrm{ppm}, \mathrm{c}, \mathrm{d}) \mathrm{Cd}$ at $200 \mathrm{ppm}, \mathrm{Pb}$ at $50 \mathrm{ppm}$, supporting electrolyte $(0.5 \mathrm{M}$ $\left.\mathrm{NaCl}+0.1 \mathrm{M} \mathrm{H}_{3} \mathrm{BO}_{3}\right), \mathrm{pH}=5$.

Table 1. AFM measurements for cathode substrate, single, and binary films electrodeposited potentiostatically at $-790 \mathrm{mV}$ ,-1025 mV vs. SCE from chloride solution respectively.

\begin{tabular}{|c|c|c|c|c|c|c|}
\hline $\begin{array}{l}\text { CSPM Imager surface } \\
\text { roughness analysis }\end{array}$ & $\begin{array}{l}\text { Roughness aver- } \\
\text { age }[\mathrm{nm}]\end{array}$ & $\begin{array}{c}\text { Root mean square } \\
{[\mathrm{nm}]}\end{array}$ & $\begin{array}{c}\text { Surface skew- } \\
\text { ness }[\mathrm{nm}]\end{array}$ & $\begin{array}{l}\text { Surface kur- } \\
\text { tosis }[\mathrm{nm}]\end{array}$ & Peak-peak $[\mathrm{nm}]$ & $\begin{array}{l}\text { Ten point height } \\
{[\mathrm{nm}]}\end{array}$ \\
\hline St.St substrate & 0.047 & 0.0589 & -0.666 & 3.15 & 0.318 & 0.194 \\
\hline $\mathrm{Pb}(50)$ & 1.9 & 2.32 & -0.564 & 2.68 & 11.2 & 6.61 \\
\hline $\mathrm{Cd}(50)$ & 1.65 & 2.06 & -0.669 & 3.15 & 10.6 & 6.33 \\
\hline $\mathrm{Pb}(200)$ & 1.52 & 1.87 & -0.468 & 2.63 & 9.09 & 4.53 \\
\hline $\mathrm{Cd}(200)$ & 1.18 & 1.44 & -0.491 & 2.51 & 6.36 & 3.56 \\
\hline $\mathrm{Cd}-\mathrm{Pb}(50: 50)$ & 2.88 & 3.53 & -0.517 & 2.57 & 15.9 & 8.94 \\
\hline $\mathrm{Cd}-\mathrm{Pb}(200: 200)$ & 1.97 & 2.4 & -0.505 & 2.51 & 11.7 & 6.59 \\
\hline $\mathrm{Cd}-\mathrm{Pb}(50: 200)$ & 2.73 & 3.39 & -0.534 & 2.81 & 17.5 & 9.43 \\
\hline $\mathrm{Cd}-\mathrm{Pb}(200: 50)$ & 2.49 & 3.04 & -0.562 & 2.57 & 13.7 & 7.11 \\
\hline
\end{tabular}

and the roughness was decreased as the concentration of either metals increased. For the binary systems, $\mathrm{Sq}$ values are 2.88, 1.97, 2.73 and $2.49 \mathrm{~nm}$ for $\mathrm{Cd}-\mathrm{Pb}$ binary system with concentration ratios (50:50),
(200:200), (50:200), (200:50) respectively. It can be seen that increasing the concentration of either ions with fixing the other lead to decrease the roughness, also increasing the concentration of these ions 


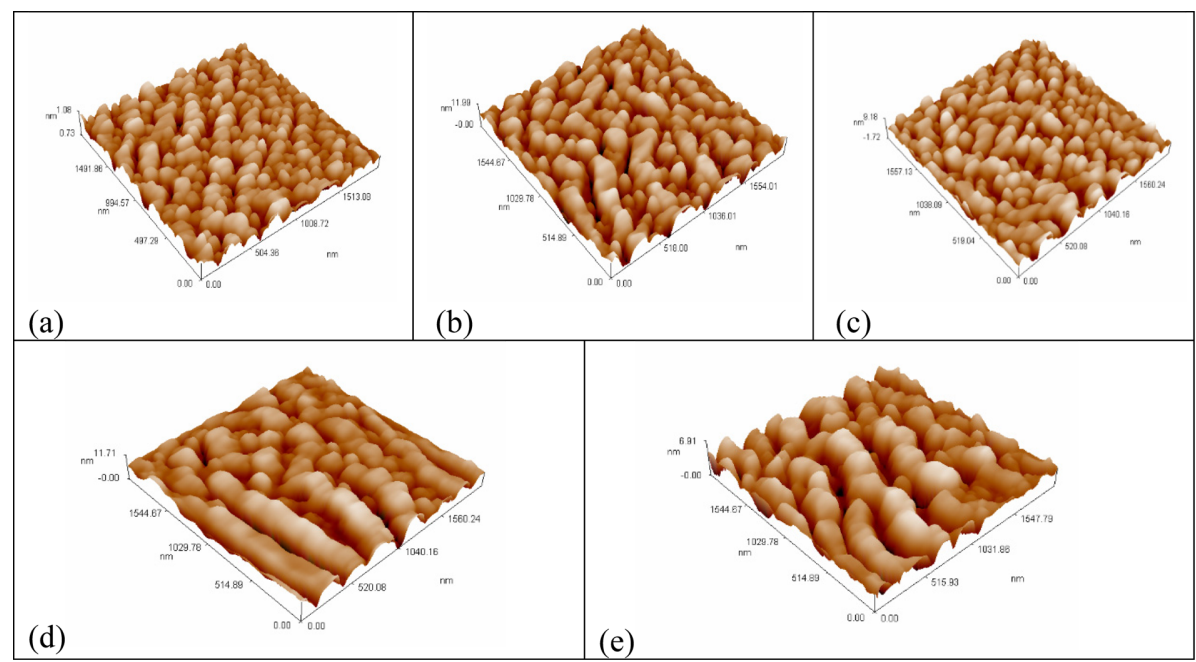

Fig. 11. AFM images of st.st substrate, $\mathrm{Pb}$ and $\mathrm{Cd}$ films electrodeposited potentiostatically at $-790 \mathrm{mV},-1025 \mathrm{mV}$ vs. SCE: a)St.St, b)Pb at $50 \mathrm{ppm}, \mathrm{c}) \mathrm{Pb}$ at $200 \mathrm{ppm}, \mathrm{d}) \mathrm{Cd}$ at $50 \mathrm{ppm}$, e)Cd at $200 \mathrm{ppm}$,supporting electrolyte $(0.5 \mathrm{M} \mathrm{NaCl}+0.1 \mathrm{M}$ $\left.\mathrm{H}_{3} \mathrm{BO}_{3}\right), \mathrm{pH}=5$.

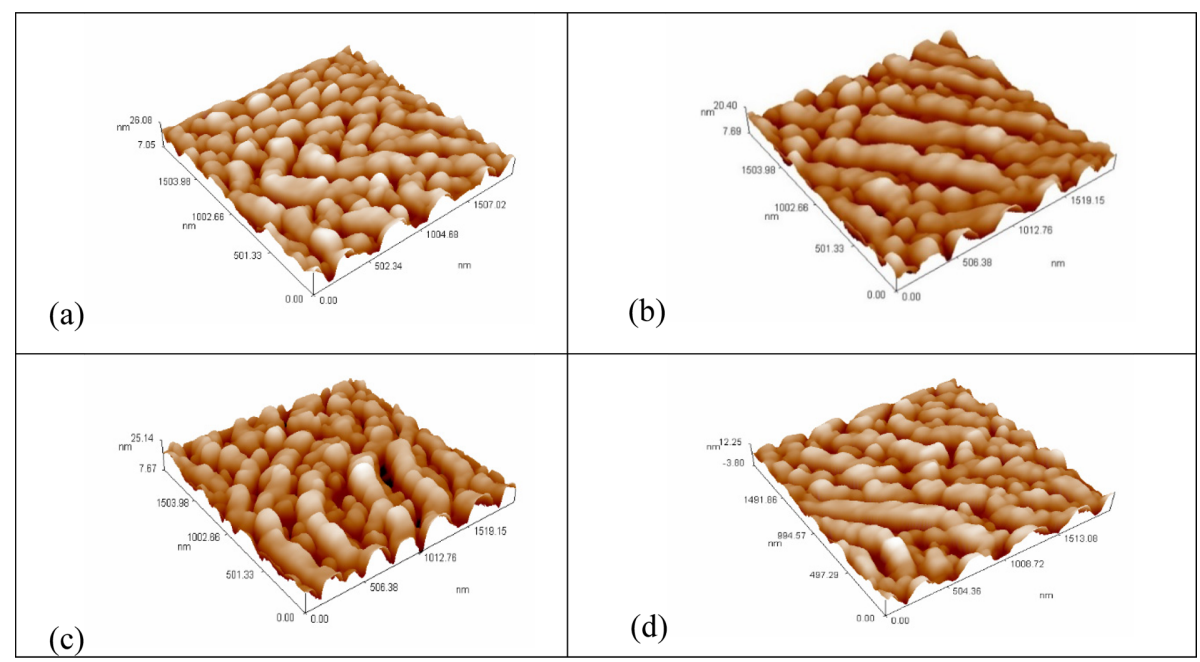

Fig. 12. AFM images of $\mathrm{Cd}-\mathrm{Pb}$ films electrodeposited potentiostatically at $-1025 \mathrm{mV}$ vs. $\mathrm{SCE}: \mathrm{a}) \mathrm{Cd}, \mathrm{Pb}$ at $50 \mathrm{ppm}, \mathrm{b}) \mathrm{Cd}, \mathrm{Pb}$ at $200 \mathrm{ppm}, \mathrm{c}) \mathrm{Cd}$ at $50 \mathrm{ppm}, \mathrm{Pb}$ at $200 \mathrm{ppm}, \mathrm{d}) \mathrm{Cd}$ at $200 \mathrm{ppm}, \mathrm{Pb}$ at $50 \mathrm{ppm}$, supporting electrolyte $(0.5 \mathrm{M} \mathrm{NaCl}+0.1 \mathrm{M}$ $\left.\mathrm{H}_{3} \mathrm{BO}_{3}\right), \mathrm{pH}=5$.

together lead to decrease the roughness. An important point to be mentioned is the influence of nucleation mechanism on the surface roughness of the deposits. It was observed that the roughness was much higher when the deposition process was denominated by progressive formation of nuclei. Therefore cadmium deposited at concentration $50 \mathrm{ppm}$ was rougher than cadmium obtained at concentration $200 \mathrm{ppm}$ because the mechanism of nucle- ation was progressive at low concentration, this observation had been confirm by Minford et al. [53]. The roughness of cadmium was less than lead in spite of the nucleation process is a progressive type. This may be interrupted as the growth of Cd crystals is controlled by adsorption in combination with nucleation process [50]. The results refer that all films have negative surface skewness which means that surface has more valleys than peaks. Surface kurto- 
sis for Cd film deposited at $50 \mathrm{ppm}$ was higher than 3 while the others were lower than 3 indicating a flat surface (Platykurtic).

\section{Conculusions}

$\mathrm{Cd}-\mathrm{Pb}$ films have been successively electrodeposited from diluted chloride solution using St.St cathode under different metal ion concentration ratios. The electrodeopsition of the single metals is mass transfer controlled process when the ion concentration is $50 \mathrm{ppm}$ or $200 \mathrm{ppm}$ as revealed by RDE voltammetry. Linear sweep voltammety curves of electrodeposition of binary metals show that electrodeposition start at cathodic potential lies between the potentials of the two single metal ions and a crossing could be occurred between the single curves depending on the concentration ratios of these metals. The ALSV curves elucidate two well-defined of dissolution peaks for lead and cadmium at different concentration ratio. Based on ALSV measurements, it is possible to anticipate the phases present in the binary metal films. The peaks of these phases are situated between the dissolution potentials of single metals, their height depends on the potential under which the cathodic co-deposition of the binary system is proceeded. The relative heights of these peaks represent the weight percent ratio of these metals in deposited film as revealed by XRD results.

The experimental results indicate that the nucleation process in the codeposition of two metal ions depends on the interaction between ions and which is controlled the nucleation process, therefore it may be similar or not to the nucleation process of individual ions. Also increasing ion concentration lead to shifting the nucleation from progressive to instantaneous model. The Chronoamperometry combined with AFM is a successful experimental approach for characterizing the films deposited electrochemically. Based on the results of CP and AFM, the progressive nucleation always leads to higher roughness of the surface than instantaneous nucleation process, also increasing the concentration will give smooth surfaces.

\section{Acknowledgment}

The authors express their gratitude to Engineering Consulting Bureau/ Al-Qadissya University for financial support of this work under the contract no.28-2.Special thanks is extended to Dr. A. Kareem ALSamaraee for his scientific helpful guidance in AFM analysis.

\section{References}

[1] D. Pletcher and F.C. Walsh, Industrial Electrochemistry, Chapman and Hall (1990).

[2] R.D. Armstrong, M. Todd, J.W. Atkinson, and K. Scott, J. Appl. Electrochem., 26, 379 (1996).

[3] R. Naseem and S.S. Tahir, Water Res., 35, 3982 (2001).

[4] J.P. Chen and X. Wang, Sep. Purif. Technol., 19, 157 (2000).

[5] A.H. Hawari and C.N. Mulligan, Bioresour. Technol., 97, 692 (2006).

[6] S. Kocaoba and G. Akcin, Desalination, 180, 151 (2005).

[7] M. Mohsen-Nia, P. Montazeri and H. Modarress, Desalination, 217, 276 (2007).

[8] T. Mohammadi, A. Razmi, and M. Sadrzadeh, Desalination, 167, 379 (2004).

[9] A. Smara, R. Delimi, C. Poinsignon, and J. Sandeaux, Sep. Purif. Technol., 44, 271 (2005).

[10] S.L. Vasilyuk, T.V. Maltseva, and V.N. Belyakov, Desalination, 162, 249 (2004).

[11] C. Ahmed Basha, S. Josephine Selvi, E. Ramasamy, and S. Chellammal, Chem. Eng. J., 141, 89 (2008).

[12] J.C. Bazan and J.M. Bisang, J. Appl. Electrochem., 34, 501 (2004).

[13] C. Ahmed Basha, K. Ramanathan, R. Rajkumar, M. Mahalakshmi, and P. Senthil Kumar, Ind. Eng. Chem. Res., 47, 2279 (2008).

[14] C.A.R. Ragnini, R.A. Di Iglia, W. Bizzo, and R. Bertazzoli, Water Res., 34, 3269 (2000).

[15] C.Y. Cheng, G.H. Kelsall and D. Pilone, J. Appl. Electrochem., 35, 1191 (2005).

[16] A.H. Sulaymon, A.O. Sharif, T.K. Al-Shalchi and A.H. Abbar, Journal of Chemical Science and Technology, 2, 175A (2013).

[17] E. Elsherief, Electrochim. Acta, 48, 2667 (2003).

[18] L.H. S Gasparotto, N. Bocchi, R.C. Rocha-Filho and S.R. Biaggio, J. Appl. Electrochem., 36, 677 (2006).

[19] L.A.M. Ruotolo and J.C. Gubulin, Chem. Eng. J., 149, 334 (2009).

[20] E. Budevski, G. Staikov and W.J. Lorenz, Electrochim. Acta., 45, 2559 (2000).

[21] A. Milchev and L. Heerman, Electrochim. Acta., 48, 2903 (2003).

[22] M. Gu and Q. Zhong, J. Appl. Electrochem., 41, 765 (2011).

[23] D. Grujicic and B. Pesic, Electrochim. Acta, 50, 4426 (2005).

[24] F. Nasirpouri, ionics, 17, 331 (2011).

[25] J. Edgar. Carrera-Crespo, P. Acevedo-Pena, M. Miranda- 
Herandez, and I. Gonzalez, J. Solid State Electrochem, 17, 445 (2013).

[26] Q. Zhang and Y. Hua, J. Appl. Electrochem, 41, 705 (2011).

[27] V.D. Jovic, R.M. Zejnilovic, A.R. Despic, and J.S. Stevonic, J. Appl. Electrochem., 18, 511 (1988).

[28] J.S. Stevonic, A.R. Despic, and V.D. Jovic, Electrochim. Acta, 42, 873 (1997).

[29] V.D. Jovic, A.R. Despic, J.S. Stevonic, and S. Spaic, Electrochim. Acta, 34, 1093 (1989).

[30] J.S. Stevonic, V.D. Jovic, and A.R. Despic, J. Electroanal. Chem., 349, 365 (1993).

[31] M.R.H. deAlmeida, E.P. Barbano, M.F. deCarvalho, I.A. Carlos, J.L.P. Siqueira, and L.L. Barbosa, Surface \& coatings Technology, 206, 95 (2011).

[32] D. Eyre, D. R. Gabet, D.R. Eastham, Plating and surface finishing, 72, 113 (1985).

[33] B. Campillo, J. Genesca, J. Avila, et al., Surface Engineering, 14, 320 (1998).

[34] E.C. Weakly and H. Dicamillo, Patent US 99248064(RRT 10 Box 480, Glenwood, NM 88039, (2001).

[35] M. Paidar, K. Bouzek, M. Laurich, and J. Thonstad, Water Environ. Res., 72, 618 (2000).

[36] C.P. De Leon and D. Pletcher, Electrochim. Acta, 41, 533 (1996).

[37] A.J. Bard and L.R. Faulkner, Electrochemical methods: fundamentals and applications, Wiley, New York (2001).

[38] D.R. Gabe and P.A. Makanjuola, In: Electrochemical engineering. IChemE symposium series, 98, 309 (1986).

[39] A. Bernner, Electrodeposition of alloys, vol.1 (Academic, New York) 1963.
[40] A.R. Despic, V.d. Jovic,in P.R.E. White, J.O.M. Bockreis, and B.E.Conway(Eds.), Modern Aspects of Electrochemistry, Plenum Press., New York, 143 (1995).

[41] B.M. Jovic, Ts. Dobrovolska, U. Lacnjevac, I. Krastev, and V.D. Jovic, Electrochim. Acta , 54, 7565 (2009).

[42] Boker, Hugh, Okamoto, Hiroaki, ASM Handbook Volume 03-Alloy phase diagrams, ASM International, USA(1992).

[43] L. Skibina, J.S. Stevanovic, and A.R. Despic, Electrochim Acta, 310, 391 (1991).

[44] D. Grujicic and B. Pesic, Electrochim. Acta, 47, 2901 (2002).

[45] M.E. Hyde and R.G. Compton, J. Electronal. Chem., 549, 1 (2003).

[46] B. Scharifker and G. Hills, Electrochim. Acta, 28, 879 (1983).

[47] M.P. Pardave, M.T. Ramirez, I. Gonzales, A. Serruya and B.R. Scharifker, J. Electrochem. Soc., 143, 1551 (1996).

[48] M. Gircis and E. Ghali, J. Appl. Electrochem, 17, 1234 (1987).

[49] G. Gunawardena, G. Hills and I. Montenegro, J. Electronal. Chem., 184, 371 (1985).

[50] A.M. Abed El-Halim, J.Appl.Electrochem, 14, 587 (1984).

[51] T. Montiel,O. Solorza and H. Sanchez, J. Electrochem. Soc., 147, 1031 (2000).

[52] B.R. Kumar and T.S. Rao,digest ,Journal of nanomerials and biostructures, 7,1881 (2012).

[53] M.L. Mnford, M.L. Sartorelli, L. Seligman, and A.A. Pasa, J. Electrochem. Soc., 149, C274 (2002). 